\title{
Nigella sativa Oil Potentiates the Effects of Pioglitazone on Long Term Alloxan-Induced Diabetic Rats
}

\author{
A.F.M. Towheedur Rahman, Md. Saiful Islam, Md. Hazrat Ali, A.H.M. Khurshid Alam, \\ Md. Aziz Abdur Rahman, Md. Golam Sadik and Mamunur Rashid
}

Department of Pharmacy, University of Rajshahi, Rajshahi-6205, Bangladesh.

\begin{abstract}
The present study was designed to investigate the effects of combination of Nigella sativa oil and pioglitazone on long-term alloxan-induced diabetic rats. In short-term (two weeks) alloxan-induced diabetic rats, $N$. sativa oil (NSO) reduced significant amount of glucose in blood, TC, TG and LDL-C and increased significant amount of HDL-C compared to diabetic rats. However, pathological changes of pancreas's Islets of Langerhans were observed after long-term (four weeks) induction of alloxan in rats. Administration of NSO recovered Langerhans cells from shrinkage whereas pioglitazone displayed slight recovery. But the combination therapy showed complete recovery of Langerhans cells as compared with diabetic rats. Combination of drugs significantly reduced the TC, TG and LDL-C level as well as increased significant amount of HDL-C level to the normal level. Combination also increased DPPH free radical scavenging activity compared with diabetic rats. The results suggest that treatment with combination therapy was more effective than mono-therapy for preventing diabetes as $N$. sativa oil potentiates the effects of pioglitazone on long term alloxan-induced diabetic rats.
\end{abstract}

Key words Nigella sativa oil, Pioglitazone, Diabetes, Combination drugs, Islets of Langerhans.

\section{Introduction}

Diabetes mellitus (DM) is a metabolic disorder of carbohydrate, fat, and protein resulting in hyperglycemia due to defects in insulin secretion, insulin action, or both (Albajali et al., 2011). Insulin is the main hormone responsible for the utilization of glucose and it is produced solely by the pancreatic $\beta$-cells (Alberti and Zimmet, 1998). It is a serious, complex chronic condition which is a major source of ill health all over the world. This metabolic disorder affects approximately $4 \%$ of the population worldwide and is expected to increase by $5.4 \%$ in 2025 (Kim et al., 2006).

Hyperglycemia resulting from unregulated glucose level is widely recognized as the causal link between diabetes and diabetic complications. It was found that hyperglycemia cause tissue damage by mechanisms involving repeated changes in cellular metabolism (Robertson, 2004). One of the key metabolic pathways, as being major contributors to hyperglycemia induced cell damage, is the nonenzymatic reaction between excess glucose and several proteins (as hemoglobin and albumin) to form Advanced Glycosylated End (AGE) product (Lapolla et al., 2005). Production of AGE interferes with cell integrity by modifying protein function or by inducing receptors mediated production of Reactive Oxygen Species (ROS) (Thornalley, 2002).

Hyperglycemia-evoked oxidative stress plays a crucial role in the development of diabetic complications, including nephropathy, neuropathy, retinopathy and hepatopathy, which is considered to result from augmented reactive oxygen species generation (Amira, 2010; Natheer, 2011) and decreased antioxidant defenses (Jin et al., 2008).

High glucose level also promotes intracellular lipid accumulation in vascular smooth muscle cells by impairing cholesterol influx and efflux balance (Xue et al., 2010). Hypercholesterolemia and hypertriglyceridemia are independent risk factors that alone or together can accelerate the development of atherosclerosis and progression of atherosclerotic lesions (Islam et al. 2012) 
Pioglitazone is used for the treatment of diabetes mellitus type 2 (previously known as non-insulindependent diabetes mellitus, NIDDM) in monotherapy and in combination with a sulfonylurea, metformin, or insulin (Berhanu et al. 2007). Pioglitazone selectively stimulates the nuclear receptor peroxisome proliferator-activated receptor gamma (PPAR- $\gamma$ ) and to a lesser extent PPAR- $\alpha$. It modulates the transcription of the insulin-sensitive genes involved in the control of glucose and lipid metabolism in the muscle, adipose tissue, and the liver (Smith, 2001). Although not clinically significant, pioglitazone decreases the level of triglycerides and increases that of high-density lipoproteins (HDL) without changing low-density lipoproteins (LDL) and total cholesterol in patients with disorders of lipid metabolism, although statins are the drug of choice for this (Berhanu et al. 2007).

On the other hand, diets play an important role in the management of hypoglycemia and dyslipidemia. Scientific investigations have shown that $N$. sativa (NS) causes direct stimulation of insulin release from isolated pancreatic Islets of langerhans in vitro (Rchid et al., 2004). The evident antidiabetic effect of NS was attributed to its insulinotropic action and the antioxidant properties which decrease the oxidative stress and preserve pancreatic $\beta$-cell integrity (Fararh et al., 2002; Rchid et al., 2004 and Kanter et al., 2003). Recently, we have shown that NS inhibits adrenaline-induced dyslipidemia and left ventricular hypertrophy $(\mathrm{LVH})$ in rats. We also suggested that NS might be used as a therapeutic alternative or as a combination with drug in the treatment of dyslipidemia and LVH (Ali et at., 2013). However, there is no published report about the combination of NSO and pioglitazone on alloxan-induced diabetic rats. Therefore, we have designed our present study to investigate the effects of NSO as a combination therapy with pioglitazone on long-term alloxan-induced diabetic rats.

\section{Materials and Methods}

Plant materials: Seeds of Nigella sativa (kalajira) were purchased from a local herbal grocery from Rajshahi city and authenticated at the Department of Botany, University of Rajshahi, Rajshahi, Bangladesh. A voucher specimen has been deposited to the herbarium in the Department of Botany, University of Rajshahi.

Preparation of seeds extract: The seeds were cleaned and dried completely under mild sun light and then ground with an electric grinder into a coarse powder. The powdered material $(300 \mathrm{~g})$ was then extracted with $96 \%$ ethanol at room temperature for nine days with occasional shaking and stirring. The extract was filtered through cotton and concentrated with a vacuum rotary evaporator to get crude extracts.

Preparation of N. sativa oil: The crude extract was then mixed with equal volume of di-ethyl-ether in a separating funnel and mixed well. Then the oily layer was collected. To wash out the water soluble impurities, the oily layer was mixed vigorously with equal volume of water. After long interval ( 24 hours) the oily layer was separated out. Finally the di-ethyl-ether was evaporated to get fresh oil of $N$. sativa (NSO).

Animal studies: All protocols for the animal experiments were reviewed and approved by the Animal Care and Use Committee of Institute of Biological Science, University of Rajshahi. Long-Evan's male rats weighing about 200-220 gm, aged 2 months, were purchased from International Centre for Diarrhoeal Disease Research, Bangladesh (ICDDR,B). Prior to commencement of the experiments, all the rats were acclimatized to the new environmental condition for a period of one week. During the experimental period, the rats were kept in a well-ventilated animal house at room temperature and were supplied with standard pellets from ICDDR,B and fresh drinking water. All the rats were kept in cages and maintained with natural 12 hour light and dark cycle. In both protocols (two weeks for short-term and four weeks for long-term), alloxan (120 mg/kg body weight, b.w.) was injected intra-peritonially (i.p.) in rats. Alloxan-induced rats were treated with i.p. injection of NSO (0.5, 1 and $2 \mathrm{ml} / \mathrm{kg} \mathrm{BW}$ ) for two weeks and NSO (2 $\mathrm{ml} / \mathrm{kg}$ b.w.), pioglitazone (10 $\mathrm{mg} / 70 \mathrm{~kg} \quad \mathrm{BW})$ and combination of both for four weeks, respectively.

Measurement of glucose level: Different doses of NSO were administered daily for two weeks and NSO, pioglitazone and combination of both for four weeks in alloxan-induced diabetic rats. Blood glucose level was determined two hours after last dose using glucometer (One Touch Horizon, USA). 
Measurement of lipid profile: After completing the treatment with $\mathrm{NSO}(\mathrm{s})$, pioglitazone and combination of both, the rats were at first anesthetized with sodium phenobarbital. Then abdominal skin was cut and thoracic artery was opened. Finally 3-5 $\mathrm{ml}$ of blood was collected directly from thoracic artery by syringe. The blood was centrifuged at $4000 \mathrm{rpm}$ for 10 minutes and the serum was obtained. Serum lipid profile, such as total cholesterol (TC), triglyceride (TG), low density lipoproteincholesterol (LDL-C) and high density lipoproteincholesterol (HDL-C), was assessed using diagnostic kits (Human, Germany).

Evaluation of free radical scavenging activity: The antioxidant activity using the 1,1-diphenyl-2picrylhydrazyl (DPPH) was assessed as described previously (Jnaszewska and Bartosz, 2002). The DPPH reduction assay was performed by adding a sample ( $20 \mu \mathrm{l}$ of blood plasma) plus $10 \mathrm{mM}$ sodium phosphate buffer (pH 7.4) to $400 \mu \mathrm{l}$ of $0.1 \mathrm{mM}$ methanol solution of DPPH. After $30 \mathrm{~min}$ incubation at ambient temperature $\left(21^{\circ} \mathrm{C}\right)$, absorbance of the samples at $517 \mathrm{~nm}$ was measured. As precipitate was formed in most of the plasma samples, they were centrifuged before the measurement.

Histopathological analysis: Histopathological studies of pancreas were performed for the investigation of pancreatic beta cell recovery of pancreas (Albajali et al., 2011). In brief, one section were obtained from each pancreas and mounted on slides and stained with haematoxyline and eosin. To evaluate the extent of pancreacyte recovery, cross-sectional images of pancreas were scanned at $\times 200$ magnifications. All images were taken by using an A. KRUSS OPTRONIC (Hamburg, Germany).

Statistical analysis: The results were expressed as mean \pm SEM. We used one-way analysis of variance (ANOVA), followed by Dunnett's post-hoc test or students paired or unpaired $t$-test where appropriate. The statistical method applied in each analysis was described in each figure. Results were considered to be significant when $p$ values were less than $0.05(p<0.05)$.

\section{Results}

The effects of NSO, pioglitazone and a combination of NSO and pioglitazone on the parameters of blood glucose level, lipid profile (TC, TG, LDL-C, HDL-C), antioxidant property and histopathology on pancreas's Islets of Langerhans morphology were performed in alloxan-induced diabetic rats.

Alloxan-induced diabetic rats were treated with NSO at different concentration $(0.5,1.0$ and $2.0 \mathrm{ml} / \mathrm{kg} \mathrm{BW})$ for two weeks to determine the appropriate dose at which most significant results were obtained and the determined dose was used to carry out the research for next four weeks protocol.

Effects of NSO on blood glucose level in short-term alloxan-induced diabetic rats: Short-term i.p. injection of alloxan in rats significantly increased blood glucose level $(335.66 \pm 7.21 \mathrm{mg} / \mathrm{dl})$ when compared with normal rats $(116.33 \pm 2.02 \mathrm{mg} / \mathrm{dl})$ (Figure 1A). To clarify the dose selection of NSO on blood glucose level, we estimated blood glucose level after two weeks treatment with different doses of NSO on alloxan-induced diabetic rats (AIDRs). Significant decrease in blood glucose level of $227.13 \pm 4.21 \mathrm{mg} / \mathrm{dl}$ and $216.6 \pm 3.93 \mathrm{mg} / \mathrm{dl}$ has been observed in NSO treated groups at dose 1.0 and $2.0 \mathrm{ml} / \mathrm{kg}$ body weight, respectively.

Effects of NSO on lipid profile in short-term alloxaninduced diabetic rats: Short-term induction of diabetes by alloxan in rats significantly altered lipid profile when compared with normal rats (Figure 1B-1E). We studied the effects of different doses of NSO $(0.5,1$ and $2 \mathrm{ml} / \mathrm{kg}$ $\mathrm{BW}$ ) on lipid profile (e.g. TC, TG, LDL-C and HDL-C levels) to select the most effective dose of NSO in AIDRs. We observed that NSO at different doses changed the lipid profile and significant change of lipid profile was found at 1 and $2 \mathrm{ml} / \mathrm{kg}$ b.w. among three doses (Figure 1B-1E). The NSO (1 and $2 \mathrm{ml} / \mathrm{kg}$ b.w.) reduced TC level $177.5 \pm 3.54 \mathrm{mg} / \mathrm{dl}$ and $172.23 \pm 2.39 \mathrm{mg} / \mathrm{dl}$ (Figure 1B), TG level $144.94 \pm 2.72 \mathrm{mg} / \mathrm{dl}$ and $136.46 \pm 2.19 \mathrm{mg} / \mathrm{dl}$ (Figure 1C), and LDL-C level $114.03 \pm 4.29$ and $98.73 \pm 3.38 \mathrm{mg} / \mathrm{dl}$ (Figure 1D), whereas the NSO increased HDL-C level $40.28 \pm 1.28$ and $51.67 \pm 2.02 \mathrm{mg} / \mathrm{dl}$ respectively (Figure 1E) when compared with AIDRs.

In two weeks protocol, we observed that the NSO doses at 1.0 and $2.0 \mathrm{ml} / \mathrm{kg} \mathrm{BW}$ exhibited significant effectiveness. Though the dose at $2.0 \mathrm{ml} / \mathrm{kg}$ BW showed slight better effectiveness than that of $1.0 \mathrm{ml} / \mathrm{kg}$ b.w., we selected the later one for four weeks protocol because the former dose revealed some unusual physical problems within AIDRs like as shivering, convulsion, anorexia and 
irregular movement. When AIDRs of this group were sacrificed, abnormalities in their digestive system were also observed (like, enlarged stomach, duodenum and large intestine). Therefore, to establish the effects of
$N$. sativa oil ( $1 \mathrm{ml} / \mathrm{kg} \mathrm{BW})$, we again had done four weeks protocol. Different parameters were measured and compared using pioglitazone alone and in combination.

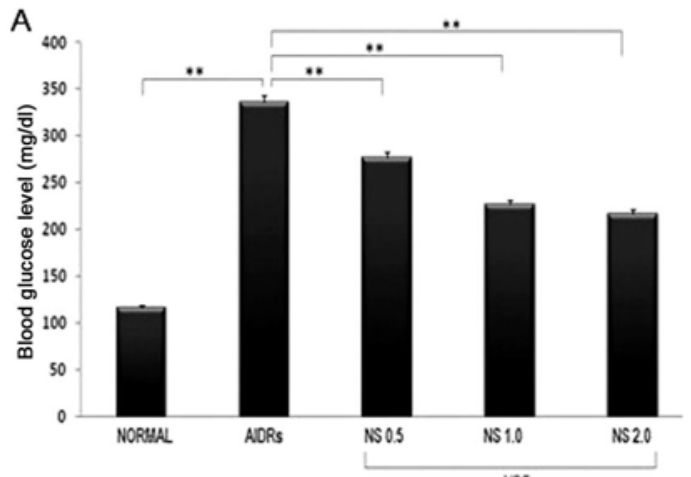

B
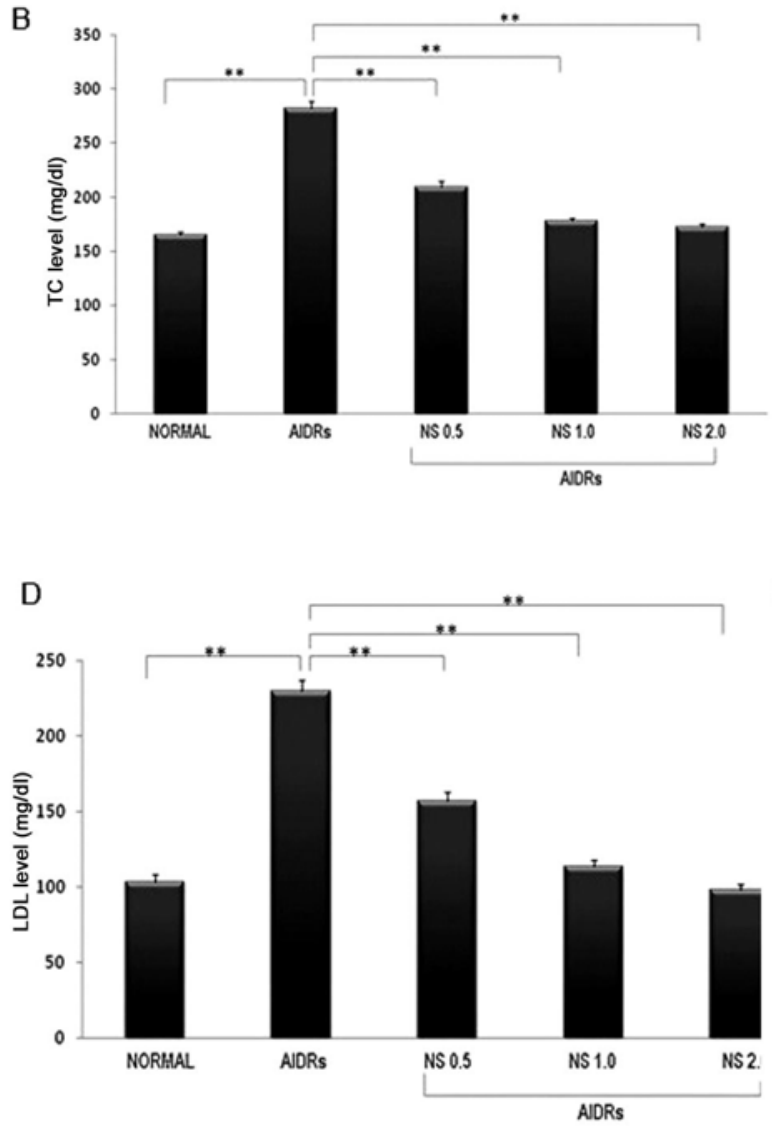

$\mathrm{C}$

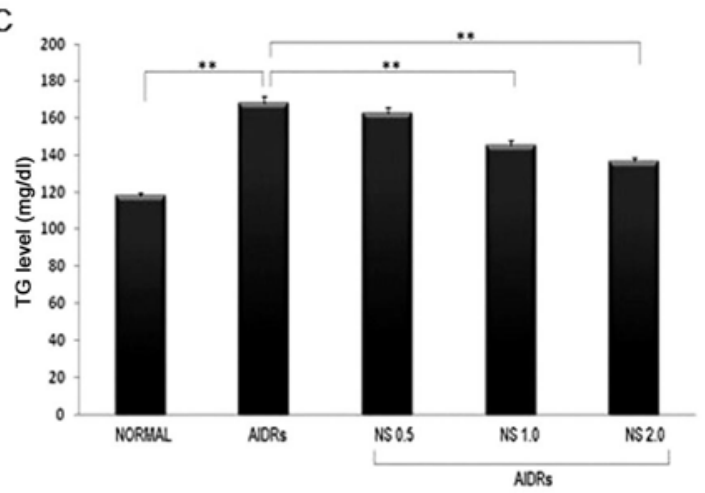

E

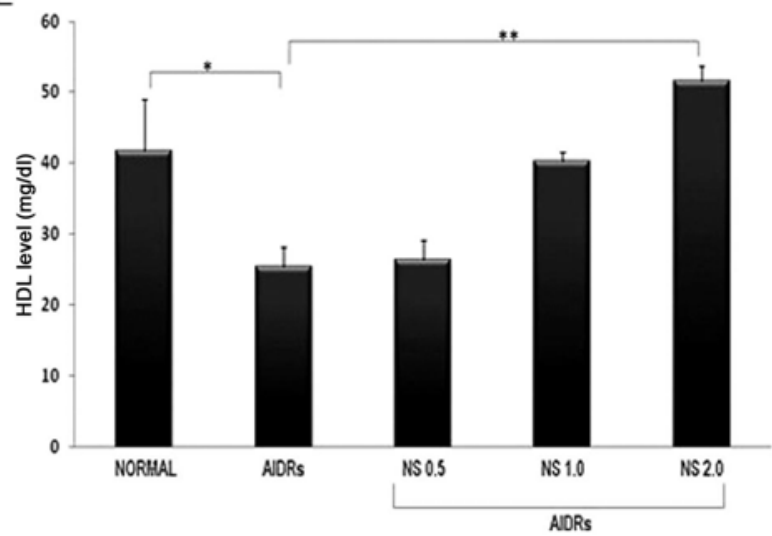

Figure 1: Effects of different doses of Nigella sativa oil (NSO) for two weeks on blood glucose level and lipid profile in short-term alloxan-induced diabetic rats (AIDRs). Figure 1A represents blood glucose level and 1B-1E represents the estimation of TC, TG, LDL and HDL-C levels, respectively. All values were presented as mean \pm SEM; $n=6$ in each group, ${ }^{*} p<0.05$ and $* * P<0.01$ compared to AIDRs. $\mathrm{NSO}=$ Nigella sativa oil, AIDRs $=$ Alloxan-induced diabetic rats.

Effects of combination therapy on blood glucose level in long-term alloxan-induced diabetic rats: Long-term i.p. injection of alloxan in rats significantly increased blood glucose level $(236.2 \pm 3.97 \mathrm{mg} / \mathrm{dl})$ when compared with normal rats $(113.1 \pm 3.77 \mathrm{mg} / \mathrm{dl})$ (Figure 2A). To investigate the effect of mono and combination therapy on 
blood glucose level in long-term AIDRs, we examined blood glucose level after four weeks treatment of NSO and pioglitazone alone and combination of both in diabetic rats. After four weeks treatment, NSO and pioglitazone decreased blood glucose level $162.34 \pm 3.58 \mathrm{mg} / \mathrm{dl}$ and $140.35 \pm 3.18 \mathrm{mg} / \mathrm{dl}$, respectively when compared with diabetic rats, but the effect of combination therapy on blood glucose level $(127.64 \pm 1.70 \mathrm{mg} / \mathrm{dl})$ was more significant than that of mono-therapy alone. Our results suggested that NSO when combined with pioglitazone more effectively reduced the blood glucose level than mono-therapy in long-term alloxan-induced diabetic rats.
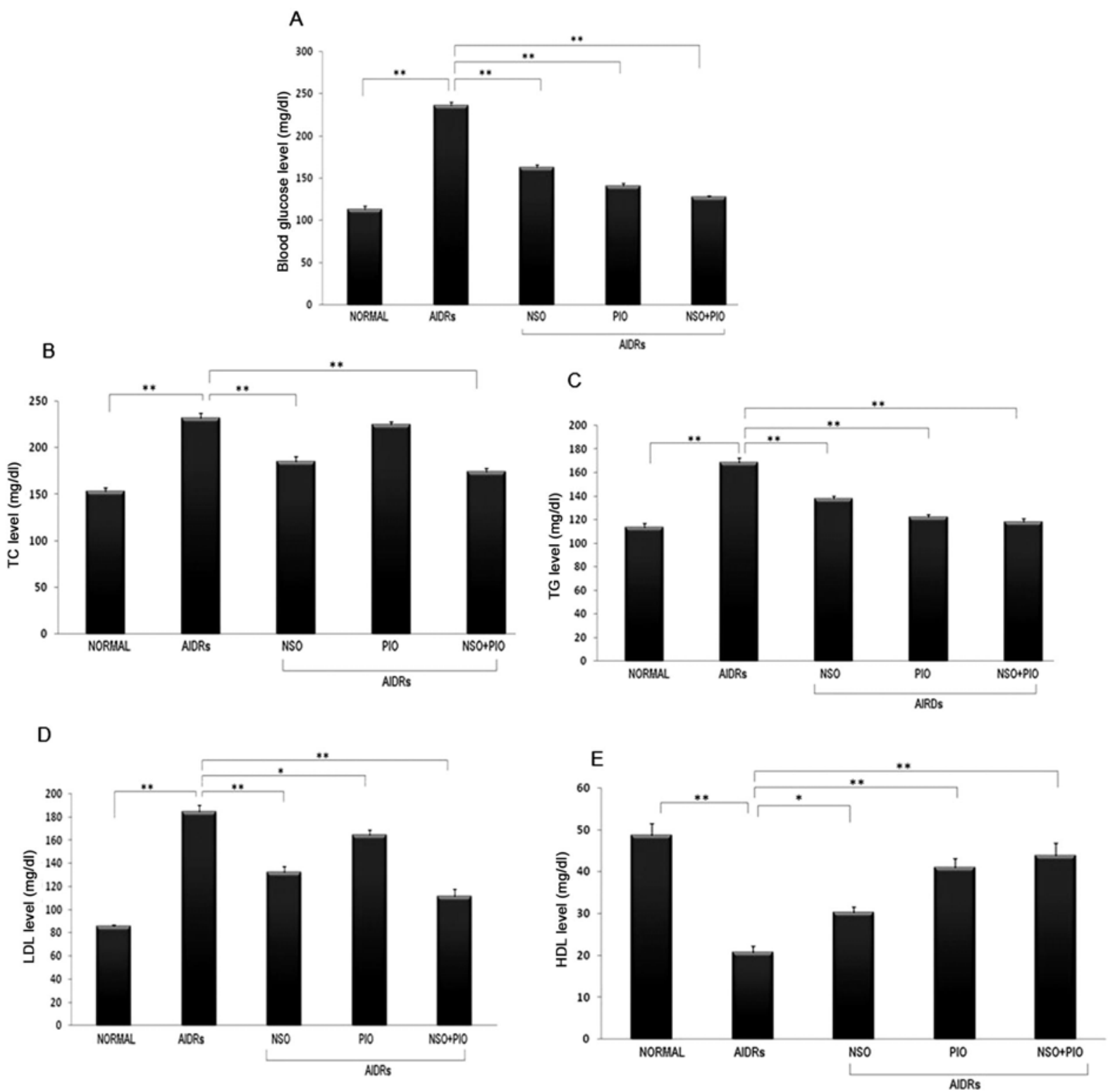

Figure 2: Effects of Nigella sativa oil, pioglitazone and combination of both for four weeks on (A) Blood glucose level and (B-E) lipid profile (TC, TG, LDL and HDL-C, respectively) in long-term alloxan-induced diabetic rats. Data were presented as mean $\pm \mathrm{SEM}$; $\mathrm{n}=6$ in each group, $* P<0.05$ and $* * P<0.01$ compared to AIDRs.

Effects of combination therapy on lipid profile in long-term alloxan-induced diabetic rats: To investigate the effects of mono and combination therapy on lipid profile, we examined TC, TG, LDL-C and HDL-C level, after four weeks treatment with NSO and pioglitazone alone and combination of both in long-term AIDRs, it was found that NSO, pioglitazone and combination of both reduced TC level $184.84 \pm 5.62, \quad 224.97 \pm 2.99$ and 
$173.90 \pm 4.49 \mathrm{mg} / \mathrm{dl}$ (Figure 2B), TG level 137.60 \pm 2.47 , $122.32 \pm 2.19$ and $117.77 \pm 3.20 \mathrm{mg} / \mathrm{dl}$ (Figure 2C), and LDL-C level $132.55 \pm 4.61,164.38 \pm 4.42$ and $111.18 \pm 6.49$ $\mathrm{mg} / \mathrm{dl}$ (Figure 2D), and they increased HDL-C level $30.21 \pm 1.32,41.01 \pm 2.07$ and $43.88 \pm 2.91 \mathrm{mg} / \mathrm{dl}$ (Figure $2 \mathrm{E})$, respectively when compared with diabetic rats. In contrast, the effect of combination therapy on lipid profile was higher than that of mono-therapy alone. These results showed that combination of NSO with pioglitazone was more effective in lipid profile than pioglitazone alone in long-term AIDRs.

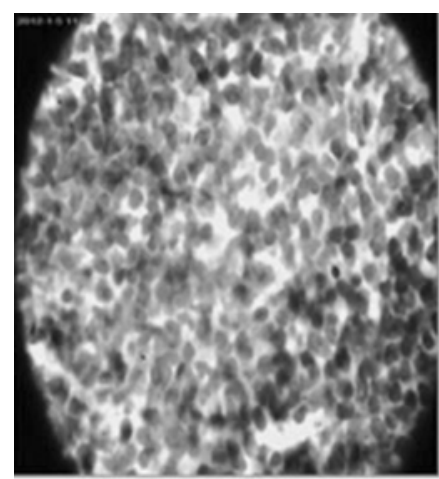

NORMAL

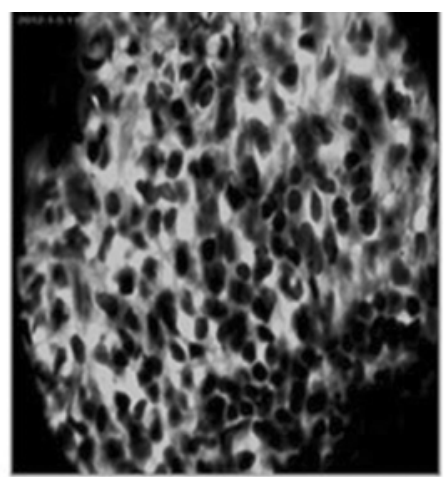

ALLOXAN

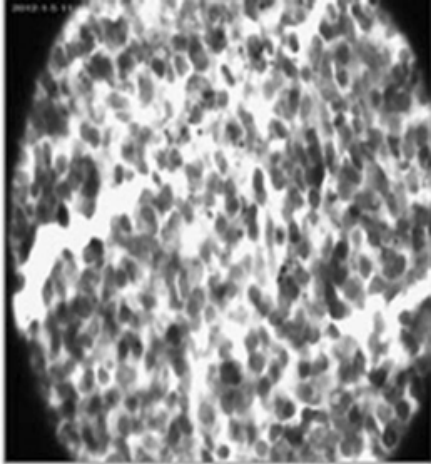

ALLOXAN+NSOIL

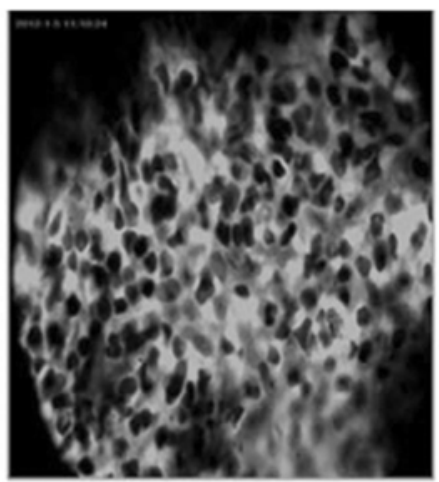

ALLOXAN+PIOGLITAZONE

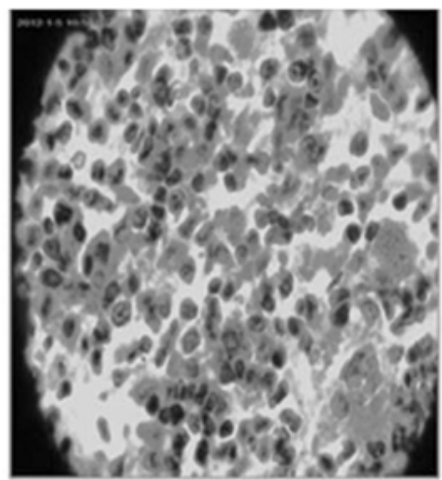

ALLOXAN+NSOIL+PIOGLITAZONE

Figure 3: A microscopic view of the effect of Nigella sativa seeds oil (NSO), pioglitazone and combination therapy on pancretic Islets of Langerhans cells morphology in alloxan induced diabetic rats (AIDRs) for four weeks.

Effects of combination therapy on DPPH free radical scavenging activity on long-term alloxan-induced diabetic rats: The effects of NSO, pioglitazone and combination of both on DPPH free radical scavenging activity were measured in long-term AIDRs. After four weeks treatment with NSO, pioglitazone and combination of both, it was observed that DPPH radical scavenging activity was increased $54.12 \%, 27 \%$ and $72.87 \%$, respectively when compared with normal control group. This result revealed that pioglitazone when combined with NSO showed better antioxidant activity $(72.87 \%)$ than that of pioglitazone alone $(27 \%)$ in long-term AIDRs.
Effect of combination therapy on pancreas's Islets of Langerhans morphology on long-term alloxan-induced diabetic rats: Injection of alloxan in rats for four weeks shrunk Islets of Langerhans in comparison with normal rats. Treatment with NSO recovered Islets of Langerhans from shrinkage in AIDRs (Figure 3). Pioglitazone alone exhibited slight effects on Langerhans cell recovery, however, when combined with NSO, a complete recovery of Langerhans cell was observed.

\section{Discussion}

Little scientific evidence exists to support the numerous herbs used to improve diabetes-related 
metabolic disorders. Diabetes, dyslipidemia and cardiovascular disease (CVD) are a common debilitating illness among peoples in both developed and developing countries. Simple life style adjustments, such as a healthy diet and physical activity, often combined with medication have been shown to be effective in promoting a full and healthy life with diabetes. Though it may be true, but the maximum diabetic patient can't take care to prevent the diabetes through life style innervations. For these reasons, it is known that considerable medical resources have been invested on the prevention and control of the diabetesrelated complications. The combination of NSO and pioglitazone may be used as an effective medicine in the treatment of diabetes and diabetes related risk factors.

In the present study, diabetes was induced in rats by injecting alloxan $(120 \mathrm{mg} / \mathrm{kg}$ b.w.) i.p. (Vadivelan et al., 2011). Alloxan is cytotoxic agent induced diabetes in a wide variety of animal species by damaging insulin secreting $\beta$-cell, resulting in decrease of endogenous insulin release, which paved the way for the decrease utilization of glucose by the tissues. Hypercholesterolemia and hypertriglyceridemia are common complications of diabetes mellitus in addition to hyperglycemia (Hossain et al., 2010). This work has evaluated the effect of NSO on the antidiabetic activity of pioglitazone in rats, and also on other important biochemical parameters, such as oxidative properties, pancreas's Islets of Langerhans morphology.

Effects of mono-therapy and combination therapy on blood glucose level: The present study showed that NSO and pioglitazone alone produced significant decrease in blood glucose level in AIDRs. Our findings supported the findings of previously published reports (Najmi et al., 2008; Kaleem et al., 2006). Interestingly, we observed that the activity of pioglitazone was increased significantly when combined with NSO for controlling diabetes in long-term alloxan-induced diabetic rats. However, further studies are needed to clarify the exact mechanism of this effect of combination therapy.

Effects of monotherapy and combination therapy on lipid profile: It had been revealed that TG accumulation increased considerably in diabetes mellitus (Iams and Wexler, 1997). Hypercholesterolemia and hypertriglyceridemia had been reported to occur in diabetic (Sharma et al., 1996). A significant increase in TC, TG, and LDL-C level; and decrease in HDL-C level observed in our experiment as compared to normal rats in four weeks protocol of diabetic rats. The serum TC, TG, LDL-C levels were significantly decreased and HDL-C level was significantly increased, after four weeks treatment with combination therapy compared to AIDRs. Our findings agreed with previously published reports except TC level in case of pioglitazone (Berhanu et al., 2006). Interestingly, the combination therapy was more significant than pioglitazone therapy alone.

Effects of combination therapy on DPPH radical scavenging activity: It had been reported that hyperglycemia increased oxidative stress (Turko et al., 2001), and oxidative stress was responsible for the CVD. Free radicals can cause damage to cardinal cellular components such as lipids, proteins, and nucleic acids (e.g. DNA), leading to subsequent cell death. The damage can become more widespread due to weakened cellular antioxidant defense systems (Jin et al., 2008). In our study, it was observed that NSO significantly increased the DPPH radical scavenging activity of pioglitazone in combination therapy on long-term alloxan-induced diabetic rats than single drug alone. Our study may suggest that NSO together with pioglitazone might be more effective for reducing the oxidative stress associated with diabetic rats. The antioxidant effect of NSO seemed to be due to its oil, thymoquinone (TQ), flavonoids and also antioxidant vitamins like vitamin E. It was shown that the seed oil and TQ inhibit non-enzymatic lipid peroxidation in liposomes and both of them especially TQ, worked as a scavenger of various reactive oxygen species, including superoxide anion and hydroxyl radicals (Padhye et al., 2008).

Effect of combination therapy on pancreas Islets of Langerhans morphology: Injection of alloxan in rats for four weeks significantly shrunk Islets of Langerhans in comparison with normal rats (Singh and Gupta, 2007). At our present study, we showed that combination therapy completely recovered Islets of Langerhans from shrinkage in AIDRs. The attributed anti-hyperglycemic effects of NSO is due to their ability to restore the function of pancreatic tissues by improving $\beta$-cell integrity, causing an increase in insulin output in insulin dependant processes. Pioglitazone restore insulin sensitivity in liver and peripheral tissues by modulating transcription of insulin sensitive gene by stimulating nuclear receptor, PPAR $\gamma$ and PPAR $\alpha$. Hence, treatment with combination 
therapy has an effect on protecting $\beta$-cell and revives insulin secretion and improves insulin resistance in liver and peripheral tissues so that smoothing out fluctuation in glucose levels and cholesterol biosynthetic pathway.

\section{Conclusion}

Alloxan-induced diabetes in rats represents wellestablished animal model for both types of diabetes mellitus. Increased production of high levels of oxygen free radicals had been linked to glucose oxidation and non-enzymatic glycation of proteins. Furthermore, characteristic diabetes raised LDL-C level, lowered HDL$\mathrm{C}$ level and elevated TG level which contributed the development of diabetic complications. Our study also revealed that long term induction of diabetes by alloxan produced shrinkage of Islets of Langerhans. The present study clearly indicated that the combination therapy possessed hypoglycemic, antidyslipidemic effects and antioxidant property and had the beneficial effects for recovering shrinkage of Islets of Langerhans than single pioglitazone therapy. Therefore, the present study suggested that NSO (1 $\mathrm{ml} / \mathrm{kg} \quad$ b.w.) together with pioglitazone might be effective antidiabetic as NSO potentiates the effect of pioglitazone in the treatment of diabetes. Hence, we may conclude that it will be more convenient to take pioglitazone in combination with diet like $N$. sativa, that are cheaper and possesses no side effect as compared to the commercially available expensive medicine like sulfonylurea, metformin, and insulin. However, further study is necessary to clarify the exact mechanism of inhibitory action of combination drugs on diabetes with other disorders.

\section{Acknowledgement}

The authors thank Square Pharmaceuticals Ltd, Bangladesh for its kind gift of pioglitazone

\section{References}

Albajali, A.A., Nagi, A.H., Shahzad, M., Ullah, M.I. and Hussain, S. 2011. Effect of Allium sativa L. on pancreatic $\beta$. cells incomparison to Nigella sativa L. in streptozotocin induced diabetic rats. J Med Plants Res. 5, 5779-5784.

Alberti, K.G. and Zimmet, P.Z. 1998. Definition, diagnosis and classification of diabetes mellitus and its complications. Part 1: diagnosis and classification of diabetes mellitus provisional report of a WHO consultation. Diabet. Med. 15, 539-553.
Amira, A.M.A. 2010. Oxidative stress and disease. Res. J. Immunol. 3, 129-145.

Berhanu, P., Kipnes, M.S., Khan, M.A., Perez, A.T., Kupfer, S.F., Spanheimer, R.C., Demissie, S. and Fleck, P.R. 2006. Effects of pioglitazone on lipid and lipoprotein profiles in patients with type 2 diabetes and dyslipidaemia after treatment conversion from rosiglitazone while continuing stable statin therapy. Diab. Vasc. Dis. Res. 3, 39-44.

Berhanu P, Perez A, Yu S., 2007. Effect of pioglitazone in combination with insulin therapy on glycaemic control, insulin dose requirement and lipid profile in patients with type 2 diabetes previously poorly controlled with combination therapy. Diabetes Obes Metab. 9, 512-520.

Fararh KM, Atoji Y, Shimizu Y, Takewaki T. 2002. Isulinotropic properties of Nigella sativa oil in Streptozotocin plus Nicotinamide diabetic hamster. Res Vet Sci. 73: 279-282.

Hoeg, M.J. et al. 1986. An approach to the management of hyperlipoproteinemia. J. Am. Med. Assoc. 255, 512-521.

Hossain, M.S., Ahmed, M. and Islam, A. 2010. Hypolipidemic and hepatoprotective effects of different fractions of ethanolic extract of immature leaves of mangifera indica (linn.) in Alloxan induced diabetic rats. Int. J. Phar. Sci. Res. 1, 132-138.

Islam, M.S., Alam, A.H.M.K., Rahmn, M.A.A., Ali, Y., Mamun, A., Rahman, M., Hossain, A.K.M.M. and Rashid, M. 2012. Effects of combination of antidiabetic agent and statin on alloxan-induced diabetes with cardiovascular diseases in rats. J. Sci. Res. 4, 709-720.

Iams, S.G. and Wexler, B.C. 1997. Alloxan diabetes in spontaneously hypertensive rats: gravimetric, metabolic and histopathological alterations. Bri. J. Expt. Pathol. 58, 177199.

Jin, L., Xue, H.Y., Jin, L.J., Li, S.Y. and Xu, Y.P. 2008. Antioxidant and pancreas-protective effect of aucubin on rats with streptozotocin-induced diabetes. Eur. J. Pharmacol. 582, 162-167.

Jnaszewska, A. and Bartosz, G. 2002. Assay of total antioxidant capacity: comparison of four methods as applied to human blood plasma. Scand. J. Clin. Lab. Invest. 62, 231-236.

Kaleem, M., Kirmani, D., Asif, M., Ahmed, Q., Bano, B. 2006. Biochemical effects of Nigella sativa $\mathrm{L}$. seeds in diabetic rats. Indian J. Exp. Biol. 44, 745-748.

Kanter, M., Meral, I., Yener, Z., Ozbek, H. and Demir, H. 2003. Partial regeneration/proliferation of the betacells in the Islets of Langerhans by Nigella sativa L. in streptozotocininduced diabetic rats. Tohoku. J. Exp. Med. 201, 213-219.

Kim, S.H., Hyun, S.H. and Choung, S.Y. 2006. Anti-diabetic effect of cinnamon extract on blood glucose in $\mathrm{db} / \mathrm{db}$ mice. J. Ethnopharmacol. 104, 119-123.

Lapolla, A., Traldi, P. and Fedele, D. 2005. Importance of measuring product of non-enzymatic glycation of proteins. Clin. Biochem. 38, 103-115. 
Najmi, A., Haque, S.F., Naseeruddin, M. and Khan, R.A., 2008. Effect of Nigella sativa oil on various clinical and biochemical parameters of metabolic syndrome. Int. J. Diabetes Metabolism. 16, 85-87.

Natheer, H.A. 2011. Oxidative stress, antioxidant status and lipid profile in the saliva of type 2 diabetics. Diabet. Vasc. Dis. Res. 8, 22-28.

Padhye, S., Banerjee, S., Ahmad, A., Mohammad, R. and Sarkar, F.H. 2008. From here to eternity - the secret of Pharaohs: Therapeutic potential of black cumin seeds and beyond. Cancer. Ther. 6, 495-510.

Rchid, H., Chevassus, H., Nmila, R., Guiral, C., Petit, P., Chokaïri, M. and Sauvaire, Y. 2004. Nigella sativa seed extracts enhance glucose-induced insulin release from ratisolated Langerhans Islets. Fundam. Clin. Pharmacol. 18, 525-529.

Robertson, R.P. 2004. Chronic oxidative stress as a central mechanism for glucose toxicity in pancreatic Islet beta cells in diabetes. J. Biol. Chem. 279, 42351-42354.

Sharma, S.R., Dwivedi, S.K. and Swarup, D. 1996. Hypoglycaemic and hypolipidaemic effects of Cinnamomum tamala Nees leaves. Ind. J. Exp. Biol. 34, 372-374.
Singh, N. and Gupta, M., 2007. Regeneration of beta cells in Islets of Langerhans of pancreas of alloxan diabetic rats by acetone extract of Momordica charantia (Linn.) (bitter gourd) fruits. Indian J. Exp. Biol. 45, 1055-62.

Smith U., 2001. Pioglitazone: mechanism of action. Int J Clin Pract Suppl. 121, 13-18.

Thornalley, P.J. 2002. Glycation in diabetic neuropathy: Characteristics, consequences, causes and therapeutic options. Int. Rev. Neurobiol. 50, 37-57.

Turko, I.V., Marcondes, S. and Murad, F. 2001. Diabetesassociated nitration of tyrosine and inactivation of succinylCoA:3-oxoacid CoA-transferase. Am. J. Physiol. Heart Circ. Physiol. 281, 2289-94.

Vadivelan, R., Umasankar, P., Dipanjan, M., Dhanabal, S.P., Shanish, A., Satishkumar, M.N. and Elanko, K. 2011. Antidiabetic activity of Madhumega Churanam (Siddha formulation) in alloxan induced diabetic rats. Der. Pharma. Sinica. 2, 299-304.

Xue, J., Yuan, Z., Wu, Y., Liu, Y., Zhao, Y., Zhang, Y., Tian, Y., Liu, W., Liu, Y. and Kishimoto, C. 2010. High glucose promotes intracellular lipid accumulation in vascular smooth muscle cells by impairing cholesterol influx and efflux balance. Cardio. Res. 86, 141-150. 